\section{Genetic Variation in Somatic Embryogenesis of Rose}

\author{
A. Millie Burrell \\ Department of Biology, Texas A\&M University, College Station, TX \\ 77843-3258
}

\section{R. Daniel Lineberger \\ Department of Horticultural Sciences, Texas A\&M University, College Station, TX 77843-2133}

\author{
Keerti S. Rathore \\ Institute for Plant Genomics and Biotechnology, Texas A\&M University, \\ College Station, TX 77843-2123
}

David H. Byrne ${ }^{1}$

Department of Horticultural Sciences, Texas A\&M University, College Station, TX 77843-2133

Additional index words. Quantitative inheritance, tissue culture, callus, zeatin, 2,4-D, regeneration

\begin{abstract}
Fifteen genetically diverse roses were evaluated for the ability to undergo somatic embryogenesis. Over the two media (MS and B5), two sugars (glucose and sucrose), and two explants (filaments and petiole) used, 20 to $30 \%$ of the 'Tournament of Roses' callus was embryogenic whereas only crystalline callus was produced in cultures of 'Baby Love', 'Ingrid Bergman', 'Perfume Delight', 'Prominent', 'Sunflare', and 90-202. Cultures of 'Tournament of Roses' consistently produced somatic embryos whereas 'Baby Love' produced no embryos. An $F_{1}$ progeny of 'Tournament of Roses' $\times$ 'Baby Love' was chosen to test whether the ability to undergo embryogenesis in Rosa hybrida $\mathrm{L}$. is heritable. Data collected from tests on $\mathrm{F}_{1}$ progeny between these genotypes suggest that the ability to undergo embryogenesis is indeed heritable in an additive fashion.
\end{abstract}

In an era when genetic transformation of plant material occurs routinely via insertion of foreign molecular constructs, such techniques can be applied to Rosa hybrida L., one of the most important nursery and florist crops in the world. Among the thousands of rose genotypes, potential for great improvement exists in disease resistance, vase life, color range, fragrance, and form. The modern commercial rose cultivars, most of which are complex tetraploid hybrids, are typically highly heterozygous, vegetatively propagated cultivars with various desired combinations of growth, production, color, form, fragrance, and postharvest characteristics (Gudin, 2000).

Disease and insect infestations in commercial roses are generally controlled with pesticides at a substantial expense to growers. Commercial growers apply fungicidal sprays 20 times during an average growing season to control powdery mildew alone on rose. This number increases for greenhouse-grown roses (Guillino and Garibaldi, 1995). Thus, disease resistance has been one of the

\footnotetext{
Received for publication 3 Feb. 2006. Accepted for publication 24 Apr. 2006. We thank Keith Zary for providing plant material for this project.

${ }^{1}$ To whom correspondence should be addressed;
} e-mail d-byrne@tamu.edu
Christie, 1989), barley (Komatsuda et al., 1989), rice (Takeuchi et al., 1997), grape (Mozsar and Viczian, 1996), red clover (McLean and Nowak, 1998), corn (Bronsema et al., 1997), cotton (Kumar et al., 1998), soybean (DiMauro et al., 2001), and potato (Seabrook et al., 2001). The inheritance of regenerative ability through somatic embryos depended on the species and varied from additive to dominant modes of inheritance.

The objectives of this research were 1) to screen a set of diverse genotypes for their capacity to produce embryogenic callus and 2) to evaluate the progeny of 'Tournament of Roses' $\times$ 'Baby Love' for their capacity to undergo somatic embryogenesis to elucidate the genetic component of rose to undergo somatic embryogenesis.

\section{Materials and Methods}

\section{Somatic embryogenesis in $\mathbf{1 5}$ diverse} rose genotypes

The Rosa hybrida L. genotypes screened for their ability to undergo somatic embryogenesis included 13 cultivars and two advanced selections. All were tetraploid and varied in growth habit, bloom color, and parentage (Table 1).

\section{Culture methods}

Leaf petioles and flower buds were collected 1 day before anthesis from mature field-grown plants and were surface sterilized with a $20 \%$ sodium hypochlorite solution containing 3 drops $\mathrm{L}^{-1}$ Tween- 80 for 20 minutes. After this treatment, explants were rinsed with autoclaved deionized, distilled water three times. In the laminar airflow hood, filaments were excised from the flower buds. Leaf petioles were sliced into 1-mm segments. Each explant type from the 15 genotypes was subjected to 10 replications in each of four callus induction media. A replication is defined as a petri dish containing 10 explants. Treatments consisted of either MS (Murashige and Skoog, 1962) or B5 (Noriega and Sondahl, 1991) media each with either glucose at $20 \mathrm{~g} \cdot \mathrm{L}^{-1}$, or sucrose at $30 \mathrm{~g} \cdot \mathrm{L}^{-1}$ in Scott Laboratory Gel-rite (2.4 $\left.\mathrm{g} \cdot \mathrm{L}^{-1}\right)$. The MS medium consisted of one-half MS salts and MS vitamins (Murashige and Skoog, 1962). Growth regulators consisted of 2,4-D $\left(2.0 \mathrm{mg} \cdot \mathrm{L}^{-1}\right)$ and zeatin $\left(1.5 \mathrm{mg} \cdot \mathrm{L}^{-1}\right)$. All media treatments were autoclaved for 20 minutes at $121{ }^{\circ} \mathrm{C} 15$ psi. Zeatin was filter sterilized and added to the media after autoclaving. The media was then poured into $100 \times$ 15-mm petri dishes at a volume of $20 \mathrm{~mL}$ per dish. The petri dishes containing the cultures of 10 filaments per plate were wrapped with parafilm and were incubated in the dark for 5 weeks at ambient temperatures $\left(24 \pm 3^{\circ} \mathrm{C}\right)$. The progress of the callus cultures was observed weekly under the stereoscope.

All experimental units were subcultured after 5 weeks and incubated for an additional 8 weeks. At 13 weeks, experimental units were rated for the proportion of embryogenic callus formed with respect to the total amount of callus produced on a 1 to 5-point scale, 
Table 1. Characterization of Rosa hybrida L. genotypes screened for their ability to produce somatic embryogenic callus.

\begin{tabular}{|c|c|c|c|}
\hline$\overline{\text { Genotype }}$ & Classification & Bloom color & Parentage \\
\hline All That Jazz & Shrub & Orange pink & Gitte $\times$ unreported seedling \\
\hline Baby Love & Miniature & Dark yellow & Sweet Magic $\times$ miniature seedling \\
\hline Carefree Beauty & Shrub & Medium pink & Seedling $\times$ Prairie Princess \\
\hline Crimson Glory & Hybrid tea & Dark red & Catherine Kordes seedling $\times$ W.E. Chaplin \\
\hline Dortmund & Kordesii & Medium red & Seedling $\times R$. kordesii \\
\hline Graham Thomas & Shrub & Dark yellow & $\begin{array}{l}\text { Seedling } \times(\text { Charles Austin } \times \text { Iceberg } \\
\text { seedling) }\end{array}$ \\
\hline Iceberg & Floribunda & White & Robin Hood $\times$ Virgo \\
\hline Ingrid Bergman & Hybrid tea & Dark red & Unreported seedling $\times$ unreported seedling \\
\hline Perfume Delight & Hybrid tea & Medium pink & $\begin{array}{l}\text { Peace } \times([\text { Happiness } \times \text { Chrysler } \\
\text { Imperial }] \times \text { El Capitan })\end{array}$ \\
\hline Prominent & Grandiflora & Orang & Color Wonder $\times$ Zorina \\
\hline Red Meidiland & Shrub & Red blend & Seafoam $\times($ Picasso $\times$ Eyepaint $)$ \\
\hline Sunflare & Floribunda & Yellow & Sunsprite $\times$ seedling \\
\hline Tournament of Roses & Grandiflora & Medium pink & Impatient $\times$ seedling \\
\hline SF $83-2$ & Shrub & Pink blend & $\begin{array}{l}\text { Sunflare } \times(R \text {. rugosa } \times R \text {. wichuriana } \\
\text { tetraploid })\end{array}$ \\
\hline 90-202 & Shrub & Ligl & $\begin{array}{l}\text { Basye seedling } 74-193 \times \text { Basye } \\
\text { seedling } 65-626\end{array}$ \\
\hline
\end{tabular}

where 1 point is crystalline callus only, 2 points is less than $10 \%$ embryogenic, 3 points is $10 \%$ to $19 \%$ embryogenic, 4 points is $20 \%$ to $29 \%$ embryogenic, and 5 points is more than $30 \%$ embryogenic callus. It should be noted that embryogenesis in rose rarely occurs in quantities exceeding more than $30 \%$ of the experimental unit (Noriega and Sondahl, 1991). Embryogenic callus grew much more slowly and had a more dense appearance to the cells than the nonembryogenic callus. The embryogenic callus also had a wet sheen on its surface compared with the nonembryogenic crystalline callus produced by 'Baby Love'.

Genetic study in somatic embryogenesis of $11 R$. hybrida L. 'Tournament of Roses' $\times$ 'Baby Love' progeny genotypes

Eleven progeny genotypes of the cross of 'Tournament of Roses' $\times$ 'Baby Love' in addition to the parental genotypes were used. The genotypes vary widely in growth habit, petal color, fragrance, bloom shape, and bloom size (Table 2).

\section{Callus induction phase}

All flower buds were harvested 1 day before anthesis so that the filaments were fully expanded and the flower bud was not yet exposed to insect or microbe pests. Flower buds were surface sterilized and excised as previously described. Ten filaments were placed in a Fisher $100 \times 15-\mathrm{mm}$ petri dish containing $20 \mathrm{~mL}$ B5 salt-based callus induction medium, modified only by the addition of $1 \%$ caffeic acid to reduce phenolic production of the explant tissue (Noriega and Sondahl, 1991). The petri dishes containing the explants were wrapped with parafilm and incubated in the dark. Twenty petri dishes per genotype were plated. After 13 weeks of incubation in dark conditions at $25 \pm 3{ }^{\circ} \mathrm{C}$ with a subculture of the explants at 5 weeks, the cultures were rated for embryogenic callus formation and were analyzed as previously described.

\section{Embryogenic Tissue Phase}

After 13 weeks, cultures were transferred to a B5 salt-based embryogenic tissue medium plus $1 \%$ caffeic acid. Cultures were incubated in dark conditions at $25 \pm 3{ }^{\circ} \mathrm{C}$ for 4 weeks. At the end of this period, friable embryogenic tissue was detected. This tissue was subcultured onto differentiation medium, containing MS salts plus $1 \%$ caffeic acid. After 8 weeks on this medium, the cultures were transferred onto a maturation medium containing MS salts plus $1 \%$ caffeic acid (Noriega and Sondahl, 1991). Cultures

Table 2. Characterization of 'Baby Love', 'Tournament of Roses' and their progeny.

\begin{tabular}{llccl}
\hline Genotype & \multicolumn{1}{c}{ Bloom color } & Petal no. & $\begin{array}{c}\text { Bloom diameter, } \\
\mathrm{cm}\end{array}$ & Growth form \\
\hline Baby Love & Medium yellow & 5 & 3 & Shrub \\
$98-00391$ & Light yellow & 5 & 3 & Shrub \\
$98-00392$ & Medium yellow & 5 & 5 & Shrub \\
$98-00394$ & Medium yellow & 5 & 4 & Shrub \\
$98-00395$ & Medium yellow & 10 & 4 & Shrub \\
$98-00396$ & Light yellow & 10 & 5 & Hybrid tea form \\
$98-00397$ & Apricot & 5 & 6 & Upright shrub \\
$98-00399-01$ & Light apricot & 5 & 5 & Shrub \\
$98-00399-02$ & Light pink & 35 & 5 & Hybrid tea form \\
$98-00399-03$ & Yellow/apricot blend & 15 & 4 & Upright shrub \\
$98-00399-04$ & Pink/apricot blend & 10 & 5 & Upright shrub \\
98-00399-05 & Light yellow & 10 & 5 & Upright shrub \\
Tournament of Roses & Light pink & 35 & 6 & Hybrid tea form \\
\hline
\end{tabular}

were incubated in dark conditions at $25 \pm 3$ ${ }^{\circ} \mathrm{C}$ for 14 weeks to induce starch accumulation (subculture after 8 weeks).

After 14 weeks, the cultures were rated under the stereoscope for somatic embryo production with a 1 to 6 -point scale with 1 point being friable callus but no embryos; 2 points, with less than $5 \%$ containing embryos; 3 points, with $5 \%$ to $9 \%$ containing embryos; 4 points, with $10 \%$ to $15 \%$ containing embryos; 5 points, with $15 \%$ to $20 \%$ containing embryos; and 6 points, with more than $20 \%$ of the culture containing embryos. The somatic embryos were distinguished in appearance by starch accumulation. Some of the embryos showed various stages of development from the round, globular stage to the heart-shape stage and the torpedo stage.

All the data from these experiments were subjected to the Shapiro-Wilcoxon test for normality, then Friedman's nonparametric analysis of variance and Tukey's Student range test as appropriate, using SAS computer software (SAS Institute, 1989).

\section{Results and Discussion}

\section{Somatic embryogenesis in 15 diverse rose genotypes}

The amount of embryogenic callus produced was affected by genotype, carbohydrate and basal salts used in the medium, as well as several interaction effects (genotype $x$ salt, genotype $\times$ carbohydrate, genotype $\times$ explant and carbohydrate $\times$ salt; Table 3 ). The genotype effect explained the most variation $(74.9 \%)$.

\section{Interaction effects}

The interaction effect of the genotypes with salt, carbohydrate, and explant was the result of the response of three rose genotypes: 'Carefree Beauty', 'Iceberg', and 'Red Meidiland' (Table 4). For both 'Carefree Beauty' and 'Red Meidiland', sucrose encouraged greater development of embryogenic callus than glucose, whereas with 'Iceberg' the petiole cultures on MS media elicited greater embryogenesis (data not shown). Given that these effects explained only a small amount of the experimental variation $(\sim 2.5 \%)$ versus that explained by the main genotype effect $(74.9 \%)$, it is unlikely that the genotypic differences were unduly obscured by the significant interaction effects (Table 4).

\section{Main effects}

'Tournament of Roses' produced the most embryogenic callus (ratings, 4.3-4.9) over all the media treatments whereas several genotypes only produced crystalline callus ('Baby Love', 'Ingrid Bergman', 'Perfume Delight', 'Prominent', 'Sunflare', and 90-202). The other genotypes produced low to moderate levels of embryogenic callus (ratings, 1.23.0). The large genotype effect supports previous studies that indicate the ability to undergo somatic embryogenesis in rose is genotype specific (Castillon and Kamo, 2002; Hsia and Korban, 1996; Kintzios et al., 
Table 3. Analysis of variance for 15 tetraploid Rosa hybrida L. genotypes for their ability to form embryogenic callus ${ }^{\mathrm{z}}$ on eight individual in vitro medium treatments.

\begin{tabular}{lrrrc}
\hline Source & DF & Mean square & F Value & Pr $>$ F \\
\hline Genotype & 14 & $5,896,895$ & 278.39 & $<0.0001$ \\
Carb & 1 & 92,945 & 4.39 & 0.036 \\
Salt & 1 & 635,260 & 29.99 & $<0.0001$ \\
Explant & 1 & 19,691 & 0.93 & 0.3352 \\
Genotype $\times$ salt & 14 & 101,003 & 4.77 & $<.0001$ \\
Genotype $\times$ carb & 14 & 71,255 & 3.36 & $<.0001$ \\
Genotype $\times$ explant & 14 & 34,863 & 2.39 & 0.0036 \\
Carb $\times$ salt & 1 & 120,701 & 5.70 & 0.017 \\
Salt $\times$ explant & 1 & 11,963 & 0.56 & 0.45 \\
Carb $\times$ explant & 1 & 37,274 & 1.76 & 0.18 \\
Genotype $\times$ carb $\times$ salt & 14 & 30,456 & 1.44 & 0.13 \\
Genotype $\times$ salt $\times$ explant & 14 & 4,922 & 0.23 & 0.99 \\
Genotype $\times$ carb $\times$ explant & 14 & 24,472 & 1.16 & 0.30 \\
Genotype $\times$ carb $\times$ salt $\times$ explant & 15 & 13,135 & 0.62 & 0.8603 \\
\hline Ran
\end{tabular}

Rating scale: $1=$ crystalline callus only; $2=$ less than $10 \%$ of experimental unit embryogenic; $3=10 \%$ to $19 \%$ or more of experimental unit embryogenic; $4=20 \%$ to $29 \%$ or more of experimental unit embryogenic; $5=30 \%$ or more of experimental unit embryogenic.

Table 4. Analysis of variance for 15 individual Rosa hybrida L. genotypes evaluated for the ability to undergo somatic embryogenesis.

\begin{tabular}{lcccl}
\hline Genotype & Sum of squares & Mean square & F value & Pr $>\mathrm{F}$ \\
\hline All That Jazz & 0.600 & 0.086 & 0.51 & 0.8272 \\
Baby Love & 0 & 0 & $\mathrm{n} / \mathrm{a}$ & $\mathrm{n} / \mathrm{a}$ \\
Carefree Beauty & 8.75 & 1.25 & 8.04 & $<0.0001$ \\
Crimson Glory & 3.188 & 0.455 & 1.96 & 0.072 \\
Dortmund & 2.488 & 0.356 & 1.51 & 0.1763 \\
Graham Thomas & 0.988 & 0.141 & 0.75 & 0.6287 \\
Iceberg & 8.79 & 1.26 & 5.68 & $<0.0001$ \\
Ingrid Bergman & 0 & 0 & $\mathrm{n} / \mathrm{a}$ & $\mathrm{n} / \mathrm{a}$ \\
Perfume Delight & 0 & 0 & $\mathrm{n} / \mathrm{a}$ & $\mathrm{n} / \mathrm{a}$ \\
Prominent & 0 & 0 & $\mathrm{n} / \mathrm{a}$ & $\mathrm{n} / \mathrm{a}$ \\
Red Meidiland & 5.188 & 0.741 & 4.20 & 0.0006 \\
Sunflare & 0 & 0 & $\mathrm{n} / \mathrm{a}$ & $\mathrm{n} / \mathrm{a}$ \\
Tournament of Roses & 2.388 & 0.341 & 1.87 & 0.0863 \\
SF 83-2 & 2.600 & 0.371 & 1.71 & 0.1192 \\
90-202 & 0 & 0 & $\mathrm{n} / \mathrm{a}$ & $\mathrm{n} / \mathrm{a}$ \\
\hline
\end{tabular}

Rating scale: $1=$ crystalline callus only; $2=$ less than $10 \%$ of experimental unit embryogenic; $3=10 \%$ to $19 \%$ or more of experimental unit embryogenic; $4=20 \%$ to $29 \%$ or more of experimental unit embryogenic; $5=30 \%$ or more of experimental unit embryogenic.

1999; Li et al., 2002; Marchant et al., 1996; Sarasan et al., 2001). The minor variation resulting from type of basal salt $(0.57 \%)$, carbohydrate $(0.08 \%)$, and explant $(0.01 \%)$ used gives further credence to this idea.

In all treatments, 'Tournament of Roses' produced the most embryogenic callus. Its callus was observed to be friable and characterized by small, round cells with a smooth almost wet appearance. The color was best described as ecru. In all treatments, 'Baby Love' produced a somewhat translucent crystalline callus containing no embryogenic clusters. The cells were visually larger and more loosely aggregated than the callus produced by 'Tournament of Roses'. The B5 basal salt was noted to elicit superior embryogenesis. The reduced form of nitrogen contained in this mixture has been suggested to be more readily assimilated by explants initiating embryogenesis (Trigiano et al., 1992).

Genetic study in somatic embryogenesis of $11 R$. hybrida L. 'Tournament of Roses' $\times$ 'Baby Love' progeny genotypes

The ability of the progeny to develop embryogenic callus ranged from those equal to 'Baby Love' to those equal to 'Tournament of Roses.' The genotypes (98-00394 and 9800396) that were similar to 'Baby Love' produced twice as much callus as the other lines. The callus produced was morphologically similar to the callus developed by 'Baby Love'. These two genotypes, although statistically grouped with 'Baby Love', were different because they did produce some embryogenic callus whereas 'Baby Love' never did in either experiment (Table 4). The other lines consistently produced some embryogenic callus resembling 'Tournament of Roses' in callus color and friability.

\section{Embryo development phase}

Overall, starch accumulation occurred at a significantly slower rate than reported for $R$. hybrida L. cultivar Royalty in the study after which this experimental protocol was modeled (Noriega and Sondahl, 1991). The addition of caffeic acid, omitted in the study by Noriega and Sondahl (1991), was the sole difference in the experimental protocols.

The ability of the progeny to produce embryogenic callus and to form somatic embryos exhibited ranges analogous to the extremes represented by their parents. As anticipated, genotypes 98-00394, 98-00396, and 98-00399-03 produced few embryos primarily because these genotypes had initiated insignificant and inconsistent amounts of em-
Table 5. Mean somatic embryo ratings ${ }^{z}$ of 'Tournament of Roses' $x$ 'Baby Love' progeny and parents.

\begin{tabular}{ll}
\hline Genotype & Mean $^{\mathrm{y}}$ \\
\hline Tournament of Roses & $3.80 \mathrm{a}$ \\
$98-00399-05$ & $3.70 \mathrm{a}$ \\
$98-00399-01$ & $3.45 \mathrm{a}$ \\
$98-00391$ & $3.30 \mathrm{a}$ \\
$98-00399-04$ & $2.35 \mathrm{~b}$ \\
$98-00397$ & $2.00 \mathrm{bc}$ \\
$98-00399-02$ & $1.95 \mathrm{bc}$ \\
$98-00392$ & $1.75 \mathrm{bc}$ \\
$98-00394$ & $1.40 \mathrm{de}$ \\
$98-00395$ & $1.40 \mathrm{de}$ \\
$98-00399-03$ & $1.35 \mathrm{de}$ \\
$98-00396$ & $1.05 \mathrm{e}$ \\
Baby Love & $1.00 \mathrm{e}$ \\
\hline
\end{tabular}

${ }^{\text {}}$ Rating scale: $1=$ callus friable but lacking embryos; $2=$ less than $5 \%$ of experimental unit containing embryos; $3=5 \%$ to $9 \%$ of experimental unit containing embryos; $4=10 \%$ to $15 \%$ containing embryos; $5=6 \%$ to $20 \%$ containing embryos; $6=$ more than $20 \%$ containing embryos ${ }^{y}$ Means with the same letter are not significantly different. Alpha $=0.05$, error $\mathrm{df}=247$, error mean square $=0.255$, critical value of $\mathrm{HSD}=4.731$, minimum significant difference $=0.534, \mathrm{~N}=20$ for Tukey's mean separation test.

bryogenic callus. However, upon starch accumulation, the embryos produced by these genotypes were of equal quality to those produced by the other genotypes evaluated. The embryogenic regions of 98-00394 were particularly slow at accumulating starch, initiating the process 5 weeks after starch accumulation was observed in genotype 98-00399-02 (Table 5).

The genotype 98-00395 showed a maturation pattern different from the others. This genotype developed substantial embryogenic callus, which was followed by $65 \%$ of the callus desiccating. This desiccation was characterized by a browning of the callus and a cessation of cell expansion. This likely was the result of an insufficient uptake of water from the medium possibly resulting from the production of phenolic compounds by the tissue, as reported by Barkosky and Einhellig (2003). The other $35 \%$ of the callus of 98-00395 demonstrated slow starch accumulation and a tendency toward similar desiccation, although sporadic regions of somatic embryos continued to develop. However, its habit of desiccating after callus initiation skewed the observation data, resulting in $65 \%$ of the experimental units ranked as containing no embryos and $35 \%$ at a lower ranking than the initial embryogenic callus would have suggested. Nevertheless, there was a good correspondence between the genotype's ability to form embryogenic callus and its ability to form somatic embryos.

The vast differences of embryogenic ability observed among the 15 unrelated rose genotypes and the spectrum of somatic embryogenesis observed in the 11 'Tournament of Roses' $\times$ 'Baby Love' progeny genotypes support the claim that the ability to undergo somatic embryogenesis is under genotypic control (Loiseau et al., 1996). The similarity in the midparental and progeny means as well as the distribution of the progeny for both 
data sets indicate an additive mode of inheritance for the plants' ability to produce embryogenic callus and somatic embryos.

Further investigation into the embryogenic ability of backcrosses and $\mathrm{F}_{2}$ populations could provide additional insight into the inheritance of this trait. By understanding the genes controlling somatic embryogenesis, the hurdles of regeneration could be overcome by breeding strategies designed to incorporate the regenerative trait into progeny.

We thank Keith Zary for providing plant material for this project.

\section{Literature Cited}

Barkosky, R.R. and F.A. Einhellig. 2003. Allelopathic interference of plant-water relationships by parahydroxybenzoic acid. Bot. Bull. Acad. Sin. 44:53-58.

Bronsema, F.B.F., W.J.F. van Oostveen, and A.A.M. van Lammeren. 1997. Comparative analysis of callus formation and regeneration on cultured immature maize embryos of the inbred lines A188 and A632. Plant Cell Tissue Org. Cult. 50:57-65.

Castillon, J. and K. Kamo. 2002. Maturation and conversion of somatic embryos of three genetically diverse rose cultivars. Hort. Sci. 36:973977.

DiMauro, A.O., R.C. DeOliveira, G.A. Bonacin, J.A. DeOliveira, S.M.Z. DiMauro, and G.B. Collins. 2001. A quantitative nature of somatic embryogenesis in soybean. In Vitro Cell. Dev. Biol. Plant 37:773-777.
Gudin, S. 2000. Rose genetics and breeding. Plant Breed. Rev. 17:159-189.

Gullino, M.L. and A. Garibaldi. 1995. Diseases of roses: Evolution of problems and new approaches for their control. Acta Hort. 424:195-207.

Hernandez-Fernandez, M.M. and B.R. Christie. 1989. Inheritance of somatic embryogenesis in alfalfa (Medicago sativa L.). Genome 32:318-321.

Hsia, C. and S.S. Korban. 1996. Organogenesis and somatic embryogenesis in callus cultures of Rosa hybrida and Rosa chinensis minima. Plant Cell Tissue Org. Cult. 44:1-6.

Kintzios, S., C. Manos, and O. Makri. 1999. Somatic embryogenesis from mature leaves of rose (Rosa sp.). Plant Cell Rep. 18:467-472.

Komatsuda, T., S. Enomoto, and K. Nakajima. 1989. Genetics of callus proliferation and shoot differentiation in barley. Heredity 80 : 345-350.

Kumar, R., S.R. Dohare, V. Nath, and P. Dureja. 1985. Levels of endogenous ABA, GA3 and IAA in achenes of Rosa hybrida. Ornamental Hort. 2:60-62.

Kumar, S., P. Sharma, and D. Pental. 1998. A genetic approach to in vitro regeneration of non-regenerating cotton (Gossypium hirsutum L.) cultivars. Plant Cell Rep. 18:59-63.

Li, X., S.F. Krasnyanski, and S.S. Korban. 2002. Somatic embryogenesis, secondary somatic embryogenesis, and shoot organogenesis in Rosa. J. Plant Physiol. 159:313-319.

Loiseau, J., C. Marche, and Y. Deunff. 1996. Variability of somatic embryogenic ability in the genus Pisum L.: Effects of genotype, explant source and culture medium. Agronomie 16:299-308.
Marchant, R., M.R. Davey, J.A. Lucas, and J.B. Power. 1996. Somatic embryogenesis and plant regeneration in Floribunda rose (Rosa hybrida L.) cvs. Trumpeter and Glad Tidings. Plant Sci. 120:95-105.

McLean, N.L. and J. Nowak. 1998. Inheritance of somatic embryogenesis in red clover (Trifolium pratense L.). Theor. Appl. Genet. 97:557-562.

Mozsar, J. and O. Viczian. 1996. Genotype effect on somatic embryogenesis and plant regeneration of Vitis spp. Vitis 35:155-157.

Murashige, T. and F. Skoog. 1962. A revised medium for rapid growth and bio assays for tobacco tissue cultures. Physiol. Plant. 5:473497.

Noriega, C. and M.R. Sondahl. 1991. Somatic embryogenesis in hybrid tea roses. Biotechnology (N.Y.) 9:991-993.

Sarasan, V., A.V. Roberts, and G.R. Rout. 2001. Methyl laurate and 6-benzyl-adenine promote the germination of somatic embryos of a hybrid rose. Plant Cell Rep. 20:183-186.

SAS Institute. 1989. SAS/STAT user's guide. Version 6. SAS Institute, Cary, N.C.

Seabrook, J.E.A., L.K. Douglass, and G.C.C. Tai. 2001. Segregation for somatic embryogenesis on stem-internode explants from potato seedlings. Plant Cell Tissue Org. Cult. 65:69-73.

Takeuchi, Y., T. Abe, and T. Sasahara. 1997. Genetic analysis of plant regeneration from seed-derived calli in rice (Oryza sativa L.). Crop Sci. 37:963-965.

Trigiano, R.N., R.A. May, and B.V. Conger. 1992. Reduced nitrogen influences somatic embryo quality and plant regeneration from suspension cultures of orchardgrass. In Vitro Cell. Dev. Biol. Plant 28P:187-191. 